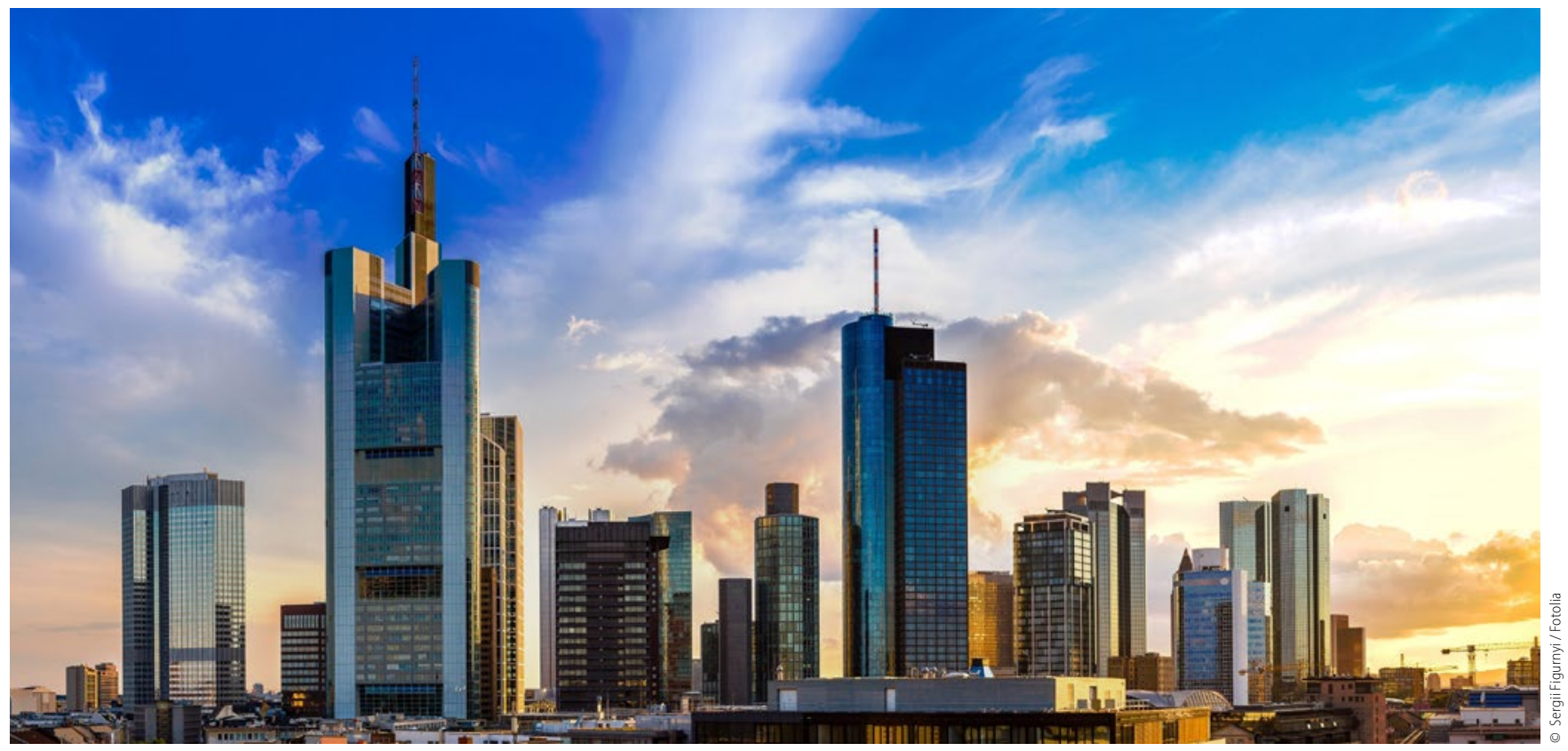

\title{
FVDZ-Bezirksgruppentreffen
}

\section{Politisch gut aufgestellt für die heiße Wahlkampfphase}

\begin{abstract}
Mit neuem politischem Schwung will der Freie Verband Deutscher Zahnärzte (FVDZ) in die gesundheitspolitische Diskussion im Bundestagswahlkampf einsteigen. Darauf verständigten sich die Vorsitzenden der FVDZ-Bezirksgruppen und der FVDZ-Bundesvorstand bei ihrer jährlichen Tagung in Frankfurt am Main.
\end{abstract}

Die Delegierten diskutierten eingehend über das neue Modell zur Stärkung der Patientensouveränität, das im neuen Grundsatzprogramm des Freien Verbandes verankert ist und einen Gegenentwurf zur von der SPD geplanten Bürgerversicherung bildet. Prof. Günter Neubauer, Direktor des Münchener Instituts für Gesundheitsökonomik, begleitet die Entwicklung des Modells wissenschaftlich und erläuterte den Bezirksgruppenvorsitzenden die Details der Modellidee. „Für uns ist das eine Strategie gegen eine kollektive Gesundheitsbeglückung der Patienten“, machte der FVDZ-Bundesvorsitzende Harald Schrader im Anschluss deutlich. „Wir rücken das Individuum und eine individuelle, selbstbestimmte Behandlung wieder in den Mittelpunkt.“ Das Modell zur Stärkung der Patientensouveränität sei „ein Prozess, der einen gesellschaftspolitischen Wandel anstoßen kann“, sagte Schrader. „Dabei müssen wir alle mitnehmen, auch die Körperschaften. Denn was wir für unsere Arbeit brauchen, ist Gestaltungsspielraum - vor allem bei der Behandlung unserer Patienten." Therapieentscheidungen müssten dort getroffen werden, wo sie hingehören: in der Praxis im Gespräch zwischen Zahnarzt und Patient.

Schrader rief die Bezirksgruppenvorsitzenden auf, die Modellidee in ihre Gruppen vor Ort zu tragen und zu diskutieren. Und noch einen Auftrag erhielten die Bezirksgruppen: „Mischen Sie sich in den Bundestagswahlkampf ein, gehen Sie zu Ihren Abgeordneten im Wahlkreis, die wiedergewählt werden wollen, oder laden Sie sie in die Praxis ein. “Denn nirgends könnten die Interessen und Angebote des Verbandes deutlicher gemacht werden als im persönlichen Gespräch. „Und dazu sind wir gut aufgestellt", betonte Schrader.

In die politische Aufbruchstimmung reihte sich die Vorstellung des neuen Existenzgründerprogrammes ein. FVDZGeschäftsführer Heinrich Bolz erläuterte das Pilotprojekt, das Anfang 2018 starten soll. Geplant sind zwölf Seminare, die junge Zahnärzte in allen Bereichen rund um die Praxisführung fit machen sollen. Die Referenten kommen entweder aus dem Verband oder sind bereits auf Kongressen und anderen Fortbildungen für den FVDZ tätig. „Unsere Kernkompetenz ist Praxis, wer könnte das besser als wir selbst“, sagte der FVDZ-Bundesvorsitzende Schrader zu dem Konzept.

Nach reichlich Input über anderthalb Tage hinweg und konstruktiven Diskussionen rund um die Themen, die derzeit den Verband bewegen, zogen die Teilnehmer ein ausgesprochen positives Fazit: „Endlich geht der Verband in die richtige Richtung“, fasste einer der Teilnehmer zusammen. sas 